\title{
Invitation from the Congress Presidents of the XXIV ICSMS Meeting
}

\author{
Anatomy 2015;9(1):49 @2015 Turkish Society of Anatomy and Clinical Anatomy (TSACA)
}

International Committee of Symposia on Morphological Sciences (ICSMS) is a permanent body, responsible for the organization of the official International Symposia on Morphological Sciences (ISMS). ICSMS organizes international symposia periodically with the aim to promote worldwide diffusion of morphological sciences and to update the scientific knowledge and research in all sectors of application of morphology and anatomical sciences.

Since the first Symposium organized with the initiative of Professor Salvador Gómez-Álvarez, in Mexico City in 1971, already 23 symposia have been successfully organized in many countries, with the participation of thousands of morphologists from all parts of the world.

The Turkish Society of Anatomy and Clinical Anatomy was rewarded to organize the XXIV ISMS, on September 2015 in Istanbul - Turkey, after the approval of our proposal by the ICSMS Executive Committee and delegates votes during the general assembly held on September 18th, 2010 in Taormina - Italy, during the XXI ISMS among five rival countries. Following the XXII ISMS in Sao Paulo - Brazil in 2012, the traditional "flag and medallion ceremony" took place in Niigata- Japan, during the XXIII ISMS in 2013.

The pressure of the perfect past symposia is our driving force to give you the best scientific and social pro- gram hoping to find a special place for Istanbul in your memories.

The wide spectrum of invited lectures and mini-symposia is compiled to represent the variety of topics concerning morphology - from clinical to ultrastructural anatomy, from neuroscience to education, biomaterials to optogenetics. The sessions are aimed to end before evening hours in order to give time to enjoy the unsurpassable beauty and history of İstanbul.

We would be honored to see you in the XXIV ISMS, which we believe would be a special meeting among all others.

\section{Co-presidents}

H. Hamdi Çelik, MD, PhD

Department of Anatomy, Faculty of Medicine, Hacettepe University

Sihhiye 06100 Ankara, Turkey

e-mail: hhcelik@hacettepe.edu.tr

\section{Erdoğan Şendemir, MD}

Department of Anatomy

Faculty of Medicine, Uludağ University

Görükle 16059 Bursa, Turkey

e-mail: demir@uludag.edu.tr

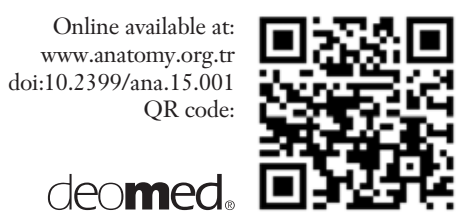

This is an open access article distributed under the terms of the Creative Commons Attribution-NonCommercial-NoDerivs 3.0 Unported (CC BY-NCND3.0) Licence (http://creativecommons.org/licenses/by-nc-nd/3.0/) which permits unrestricted noncommercial use, distribution, and reproduction in any medium, provided the original work is properly cited. Please cite this article as: Çelik HH, Şendemir E. Invitation from the Congress Presidents of the XXIV ICSMS Meeting. Anatomy 2015;9(1):49. 